International Journal of Engineering \& Technology, $7(3.12)(2018) 1278-1280$
International Journal of Engineering \& Technology
SPC
Website: www.sciencepubco.com/index.php/IJET
Research paper

\title{
Sustainability through Underground Urbanization
}

\author{
Shubham Singh ${ }^{1}$, Piyush Chaudhary ${ }^{2}$, Akshay Vashisht ${ }^{3 *}$ Jagdeep Singh $^{4}$ \\ ${ }^{1,2,3,4}$ Department of Civil Engineering, Chandigarh University, Gharuan, India \\ *Corresponding Author E-mail: ${ }^{3}$ akshayvashisht7@gmail.com
}

\begin{abstract}
Urbanization in past few decades has grabbed a huge amount of our agricultural land leading towards various climatic problems as well as endangering our sustainability. Thereby, utilizing the underground earth space instead of using land mass and its resources will transform the lifestyle and will sustain our livelihood. Civilizing and urbanizing underground ecologically enables our sustainability and will contribute to protect the natural resources for future. The better utilization of land and sustainable use of earth space will play a vital role to protect our natural resources and maintaining our sustainability. As various research and study shows our planet can sustain up to 11 billion population and we are currently 7.6 billion right now, which is considered to reach deadline till the end of this century. Therefore, utilizing underground earth space will provide enough space for building sector and agriculture sector and will serve the purpose in both ways. Thus, it is quite important to clear the way for sustainable pattern of underground civilization.
\end{abstract}

Keywords: Sustainable Development, Dual Utilization of Land, Underground Urbanization, Resource Availability.

\section{Introduction}

The massive building construction, the high-rise tower, the high density in the city; these all are the sign of a revolution and architecture that's spreading around the world. The population of our world is growing exponentially to levels never imagined, this will lead to grave consequences if it isn't managed properly. This increase in population, infrastructure \& buildings is driving a change in demands of industrial, commercial, and civil service sector. But the only biggest challenge of our future is availability of adequate energy, resources and land mass for our future growing population.
Since our essential agricultural land is disappearing under concrete and asphalt therefore its quite important to find a radical solution for this.

Thereby, urbanizing underground and utilizing the underground earth space will provide us more usable fertile agricultural land and will help us to enable our sustainability. Development of underground civilization and better utilization of underground earth will give more space to building sector and agriculture sector as well. The main target here is to maintain the level of urbanization and meet the daily requirements of urban population through land management.

\section{Need and Necessity}

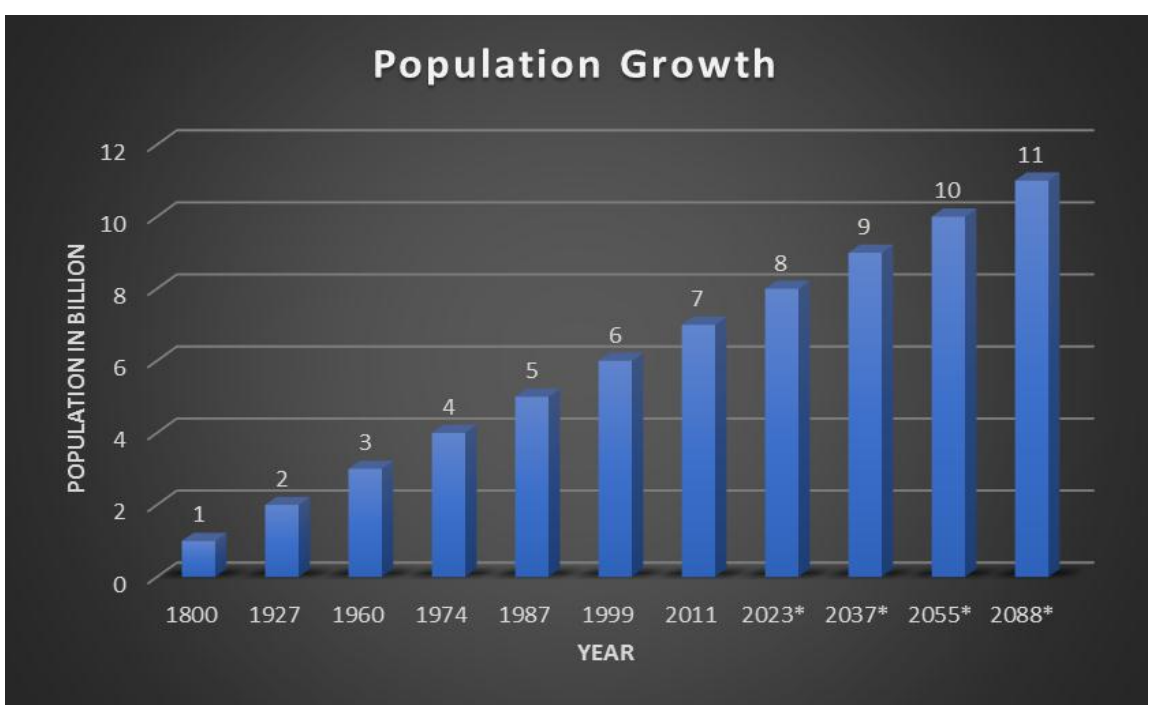

Fig. 1: Population growth graph 
The current population of our world has reached around 7.6 billion and is continuously increasing exponentially. The population is expected to be doubled till the end of this century.

According to various studies more than half of world's population is living in urban cities. Now this uncontrolled growth of population will need to meet the demands of both infrastructures and resources as well. But present condition of urban population is not capable enough to fulfill its need and meet its own demands and requirement for a standard of living.

There is tremendous revolution in usage of land for urbanization in past few decades. The high density of population and their land consumption in urban areas has built up and adverse impact on our environment leading towards scarcity of agricultural land and water. The widespread of population and depletion of fertile land has put our globe at a risk leading towards challenging task to feed these much amount of people in upcoming years.

\section{Objective}

In order to balance the development scale and requirement of sources, the purpose here is to construct a building beneath the ground level whereas the land above the building shall be utilized as agricultural land so as to meet the sustainable requirements. Hence the underground development will play a vital role in reshaping the urbanization and to protect our sustainability as the both purpose is served i.e. the livelihood and the requirements to have good livelihood.

\section{Scope for Underground Space Development}

The construction projects should be more adaptive with transformation in growing demands from urbanization. The construction industries should rethink in order to decrease land exploitation and availability of resources for sustainable development. Therefore, constructing or urbanizing towns/cities beneath the ground level will be considered as multifunctional and multilayered, by using the same land area for constructing infrastructures and cultivation purpose simultaneously. The one of the biggest challenge for our future development is land scarcity due to excessive construction in urban areas. And this excessive development is constantly occupying the farmland area endangering our sustainability. The scarcity of land is also leading to increases in land prices due to which the production of resources is declining.

Hence, the underground urbanization is definitely going to be a part of sustainable development for public infrastructure and availability of resources as well.

\section{Feasibility and Execution for Underground Urban Development}

Constructing the infrastructures beneath the ground level will require highly advanced technology and equipment as compared to conventional construction over the ground. It also need highly skilled labors for excavation and foundation purpose with high capital investment to enable the sustainability.

The process to be followed while constructing the building beneath the ground level will be same as while constructing above the ground level, such as:

\subsection{Survey and Designing Process}

It includes analysis and inspection of the construction site followed by designing, modelling and simulation.

\subsection{Construction and Execution Process:}

Excavation and execution for construction will be conducted according to need and requirements of the building to be setup
Hence, also during the excavation, the cutting and filling will be decided. Further, the respective foundation is to be provided and construction of building is to be continued as per specification.

\subsection{Operation and Controlling Process}

It includes the safety factors, interior facilities and monitoring the underground system.

\section{Designing Down for Sustainable Future}

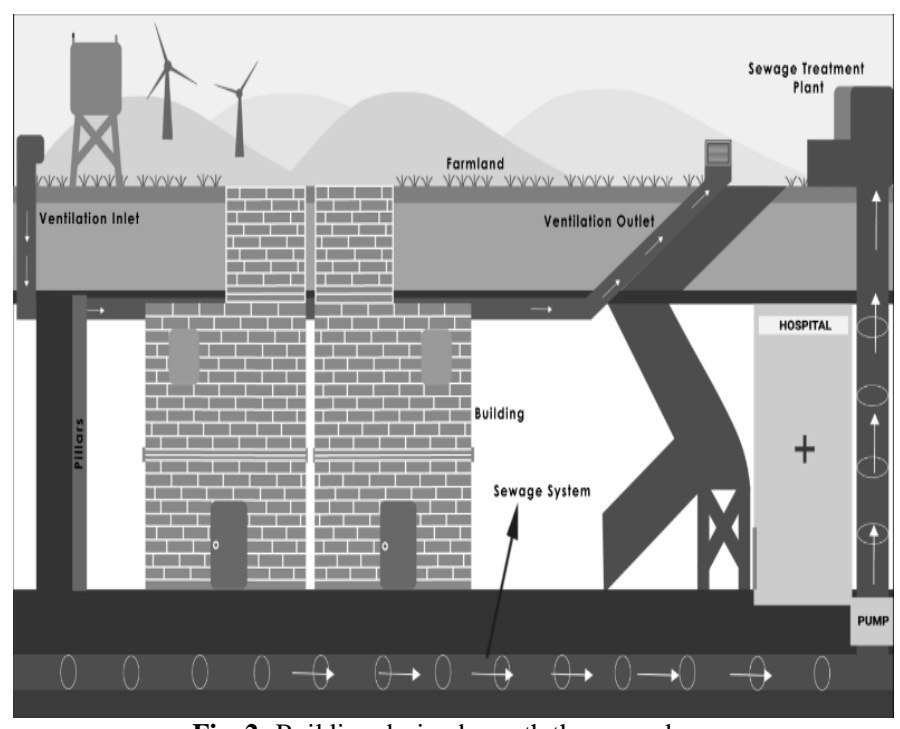

Fig. 2: Building design beneath the ground

The livelihood in underground building will require an enhanced spatial design for their living. To keep the working of building uninterrupted and fluent lifelong, the regular controlling and constant monitoring is to be done.

This design serves the purpose of ventilation as the inlet and outlets for the air to travel are clearly provided. This will lead to proper air supply with no congestion as the air will be entering through the inlet with the help of air ducts and filters attached to it and hence will be going out in the similar manner from the outlet provided.

The kitchen plays an important role here as the fire exit is present in this area which will have an opening on the ground level through a glass gate which will also allow the sunlight to enter in the kitchen area and hence the purpose will be served in both ways.

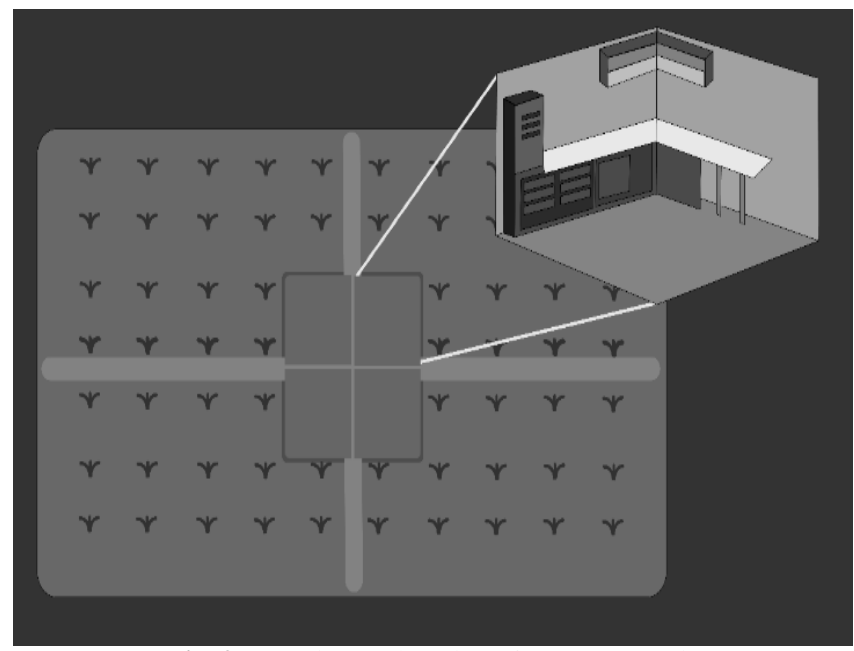

Fig. 3: Top view and section of emergency exit

The drainage provided above the structure would help the water not to percolate and affect the building. It will help the water to 
move to another path and hence no water circulation will be there to affect the structure from the soil overhead.

Whereas, the drainage provided below the building will be the sewage outlets for the building as the waste generated inside the building will have a particular way to get out and will further be divided to the respective STP's.

The demonstration of the designed building is shown in the figures.

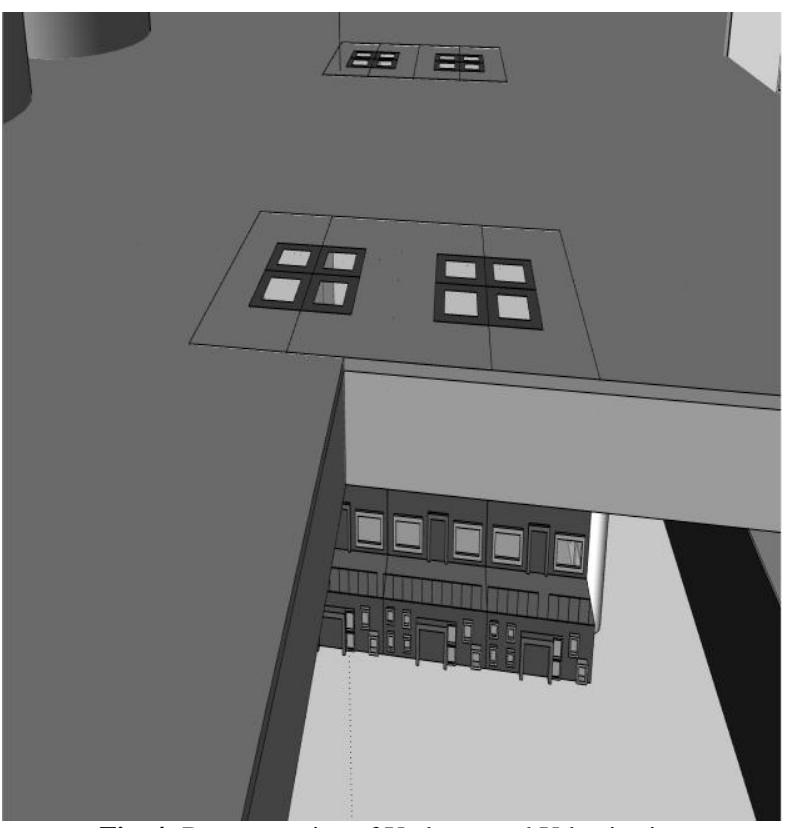

Fig. 4: Demonstration of Underground Urbanization

\section{Practical Advantages and Specifications of Underground Designed Buildings}

1. The building and environment inside will stay safe from extreme weather condition like wind, storm, hailstorm etc.

2. The Environment beneath the ground will also be pollution free.

3. The environment beneath the ground level will be warm in winter and cool in summer due natural insulation of soil overhead. And hence will consume less energy.

4. The building will serve green as no harmful gas will be releasing through air conditioners due to thermal insulation.

5. Better Site Utilization: The building ensures the finest \& perfect usage of land, since structure is beneath the ground.

6. The underground buildings are far safer from radioactive fallouts, biological attacks and other explosive condition in case of any global conflict.

7. Sustainability is not only limited to use land in a better way but also to produce all the required resources by using the most efficient way. To justify this, this plan also helps in providing the land for the sources to be produced such as electricity.

8. Wind mill is one of the best way and source to produce the energy. Wind mills being huge in size need space to be established, to be precise an open are is needed for so. Hence to produce space for this, the building and infrastructure under the ground is the best idea.

9. Land which would be available will not be only limited to windmills planting but also the power generation can be done by using the land as the plane surface having the solar panels provided in a huge no. in a huge area. But this is only workable if the implementation and execution is done in a decent manner so that it serves the purpose for all in a huge amount. Solar panels generating electricity, being more efficient, cheap and availability of the same shall be in abundance. Again, the sustainability is not only limited for human beings. All the livestock needs the equal importance and hence considering the fact the available ground can be used by animals for the purpose of grazing and having an abundance of food that they require especially for the herbivores.

10. Solution to Deforestation: Since the land would be available for the basic need of humans, the scenario of deforestation will automatically reduce protecting us from climatic imbalance.

\section{Conclusion}

From present research and studies, it is predicted that due to overpopulation in coming 200 years there will be no space for humans to survive over the surface. So, to serve the purpose of living one would be doing so, this design would be the most efficient way to work out.

Constructing an Eco designed building under the ground is definitely going to be sustainable step towards development. As the need and requirements of every individual will be fulfilled without exploiting the resources. This building design gives the usage of land in a productive manner and hence production of sources from the present available resources could be balanced.

This Building Design is easily workable and it is practically possible to have such a structure as the problems that can occur are solvable. If a building can have a basement rooms, then yes, it is also possible to have a building down there. Although this would be a onetime investment for the client but will serve to the environment for sure in various ways.

\section{References}

[1] "The Road to Sustainability" by Federico M. Pulselli, Simone Bastianomi, Nadia Marchettini \& Enzo Tiezzi

[2] "The dimensions of global urban expansion, estimates and projections for all countries, 2000-2050" by S. Angel, J. Parent, D.L Civco \& David Potere.

[3] "Compact Cities: Sustainable Urban Forms For Developing Countries.” By M. Jenks, R. Burgees

[4] "World Population Prospects, 2017" by United Nations

[5] "Word Population to 2300" - Economic and Social Affairs, United Nations.

[6] "Think Deep: Planning, development and use of underground spaces in cities" - ISOCARP, ITACUS

[7] "Underground Development: A springboard to make city life better in 21st century" by Dimitris Kaliampakos, Procedia Engineering Volume 165, 2016, Pages 205-213.

[8] "Transitions to a high density urban underground space" by Nikola Bobylev, Procedia Engineering 165 ( 2016 ), Pages 184-192. 